\title{
How do patients' clinical phenotype and the physiological mechanisms of the operations impact the choice of bariatric procedure?
}

This article was published in the following Dove Press journal:

Clinical and Experimental Gastroenterology

22 July 2016

Number of times this article has been viewed

\section{Thomas Bächler' \\ Carel W le Roux ${ }^{2,3}$ \\ Marco Bueter ${ }^{4}$}

'Department of General and Visceral Surgery, Fribourg Cantonal Hospital

(HFR), Fribourg, Switzerland;

${ }^{2}$ Diabetes Complications Research

Centre, Conway Institute, University

College Dublin, Dublin, Ireland;

${ }^{3}$ Gastrosurgical Laboratory, University

of Gothenburg, Gothenburg,

Sweden; ${ }^{4}$ Division of Visceral and

Transplantation Surgery, University

Hospital Zurich (USZ), Zürich,

Switzerland
Correspondence: Marco Bueter

Division of Visceral and Transplantation Surgery, University Hospital Zurich, Rämistrasse 100, CH - 8091 Zürich, Switzerland

$\mathrm{Tel}+4$ I 442558895

Fax +4I 442558942

Email marco.bueter@usz.ch
Abstract: Bariatric surgery is currently the most effective option for the treatment of morbid obesity and its associated comorbidities. Recent clinical and experimental findings have challenged the role of mechanical restriction and caloric malabsorption as the main mechanisms for weight loss and health benefits. Instead, other mechanisms including increased levels of satiety gut hormones, altered gut microbiota, changes in bile acid metabolism, and/or energy expenditure have been proposed as explanations for benefits of bariatric surgery. Beside the standard proximal Roux-en-Y gastric bypass and the biliopancreatic diversion with or without duodenal switch, where parts of the small intestine are excluded from contact with nutrients, resectional techniques like the sleeve gastrectomy (SG) have recently been added to the armory of bariatric surgeons. The variation of weight loss and glycemic control is vast between but also within different bariatric operations. We surveyed members of the Swiss Society for the Study of Morbid Obesity and Metabolic Disorders to assess the extent to which the phenotype of patients influences the choice of bariatric procedure. Swiss bariatric surgeons preferred Rouxen-Y gastric bypass and SG for patients with type 2 diabetes mellitus and patients with a body mass index $>50 \mathrm{~kg} / \mathrm{m}^{2}$, which is consistent with the literature. An SG was preferred in patients with a high anesthetic risk or previous laparotomy. The surgeons' own experience was a major determinant as there is little evidence in the literature for this approach. Although trends will come and go, evidence-based medicine requires a rigorous examination of the proof to inform clinical practice.

Keywords: bariatric procedures, underlying physiology, choice of type of surgery

\section{Introduction}

Previously, it was thought that caloric malabsorption and food restriction were important mechanisms determining the outcome of bariatric surgery. However, both preclinical and clinical studies revealed that complex physiological changes lead to body weight loss and beneficial metabolic changes after bariatric surgeries, such as Roux-en-Y gastric bypass (RYGB) and sleeve gastrectomy (SG). Mechanisms include altered levels of satiety gut hormones, ${ }^{1,2}$ alterations in energy expenditure, ${ }^{3-7}$ changes in bile acid levels, ${ }^{8-11}$ and modified gut microbiota. ${ }^{12-14}$ "Association" should, however, not be confused with "causation" as the measurable changes in circulating parameters after bariatric surgery do not necessarily infer a causal relationship with the benefits of surgery. It remains unclear whether these mechanisms alone or in combination with others are necessary or sufficient for reduced food intake or body weight loss. 
There are substantial variations as regards metabolic efficacy between and within different surgical techniques, which can complicate clinical decision-making. This review focusses on the most common bariatric procedures and summarizes potential underlying physiological mechanisms. Moreover, we will report on a survey among clinicians in Switzerland as to which surgical technique they prefer in different scenarios. The findings are then presented within the framework of currently available evidence.

\section{Common bariatric surgical techniques}

Currently, RYGB and SG are the most commonly performed bariatric surgeries worldwide..$^{15}$ Gastric banding (GB) has lost a lot of its popularity within the last 10 years, whereas biliopancreatic diversion with or without duodenal switch remains the operation of choice in only a few international centers..$^{15}$ The latter two procedures will therefore not be discussed in detail in this review.

Currently, bariatric procedures are almost always performed laparoscopically. ${ }^{15}$ For the RYGB, the stomach is divided into a proximal gastric pouch with a volume of about $15-30 \mathrm{~mL}$ and a distal gastric remnant (please see for preoperative anatomy Figure 1A). Similarly, the jejunum is transected approximately $50 \mathrm{~cm}$ distal to the ligament of Treitz, creating a proximal and distal end of jejunum. An anastomosis between the distal end of the jejunum and the gastric pouch (gastrojejunostomy) creates the so-called alimentary limb. The proximal end of the jejunum, still continuous with the gastric remnant, constitutes the so-called biliopancreatic limb and is anastomosed with the small bowel approximately $150 \mathrm{~cm}$ distal from gastrojejunostomy leading to formation of the common channel. Thus, after completion of the standard Roux-en-Y reconstruction, there is an alimentary limb of 100-150 cm, a biliopancreatic limb of $50 \mathrm{~cm}$, and a common channel of variable length, typically $300-500 \mathrm{~cm}$ (Figure 1B). ${ }^{16}$

For the $\mathrm{SG}$, the stomach is stapled along the big curvature creating a gastric tube of a volume of around $100-200 \mathrm{~mL}$ leading to an accelerated gastric emptying (Figure 1C). ${ }^{17}$

\section{Underlying physiological mechanisms of bariatric surgery}

For decades, the body-weight-lowering effects of bariatric procedures were mainly attributed to mechanical restriction and caloric malabsorption. However, an increasing body of evidence questions the contribution of these anatomical and mechanical explanations. Recent findings suggest the importance of physiological mechanisms including changes in gastrointestinal hormone levels, ${ }^{1,2,18,19}$ bile acid metabolism, ${ }^{8-11}$ gut microbiota, ${ }^{13,14,20,21}$ and energy expenditure, ${ }^{3-7}$ among others. Key findings pertaining to these mechanisms will be briefly introduced with a special focus on the RYGB procedure, which is the most commonly performed and studied bariatric surgery worldwide. When possible and appropriate, reference will also be made to the SG.
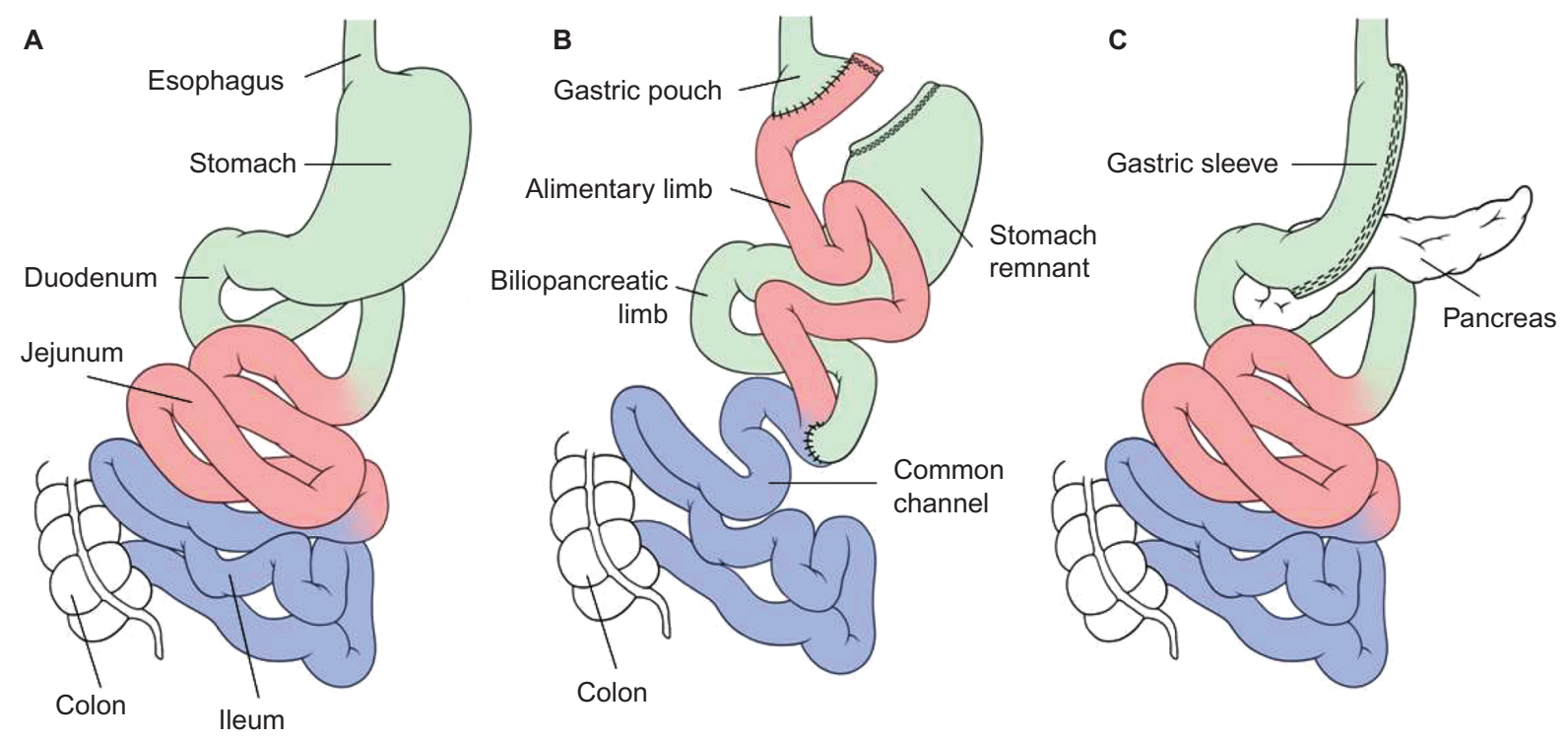

Figure I Schematic illustration of the preoperative (A) and postoperative anatomy of the gastrointestinal tract after a Roux-en-Y gastric bypass (B), and sleeve gastrectomy (C).

Note: Reproduced from Lutz T, Bueter M. Wohin geht die Anti-Obesitas Therapie? Prakt Tierarzt. 2012;93(I2):1087-1095.95 


\section{Changes in gut hormones}

The most consistent findings after RYGB in patients and animal models of RYGB are the increased secretion of satiety gut hormones after RYGB surgery. ${ }^{1,2,18,19,22,23}$ Several studies focused on altered levels of gut hormones that are known to affect food intake and to modulate nutrient metabolism. ${ }^{24-26}$ Insights into the role of gut hormones in the control of eating behavior has led to their therapeutic exploitation as possible antiobesity drugs. ${ }^{27}$

Glucagon-like peptide 1 (GLP-1) and peptide YY (PYY) responses are elevated postprandially after RYGB and SG. ${ }^{2,26,28-30}$ Circulating GLP-1 and PYY are released by the enteroendocrine L-cells when in direct contact with nutrients or bile acids in the gastrointestinal tract. ${ }^{31,32}$ When RYGB patients are divided into "good and poor responders", those with more weight loss had significantly higher postprandial GLP-1 and PYY responses. ${ }^{33}$ To examine causation of the elevated gut hormone response, blockade of these responses with somatostatin analogs resulted in increased food intake in three groups, including RYGB patients, rats after RYGB, and patients after esophagectomy with gastric conduit reconstruction (which mimics SG in both anatomy and physiology). ${ }^{2,34,35}$ However, although blockade of all postprandial gut hormones led to doubling of food intake, the amount of calories consumed was still lower than preoperative values, suggesting that other mechanisms may also play an important role., ${ }^{2,36}$

The underlying mechanisms of an increase in postprandial GLP-1 and PYY L-cell secretion after RYGB surgery remain controversial. One explanation is the exposure of the distal gut lumen to higher concentrations of undigested nutrients as distal parts of the small intestine exhibit a higher mucosal L-cell density. ${ }^{37-39}$ Alternatively, increased L-cell secretions may also be due to enhanced stimulation of L-cells by bile acids or even gut microbial interactions. . $^{31,32}$

However, measurable changes in circulating parameters after bariatric surgery do not necessarily mean that these hormones have a causal role..$^{40}$ In other words, it is not yet clear whether hormonal changes alone or in combination with other mechanisms are necessary or sufficient for reduced food intake or body weight. Most efforts trying to establish a causal role for single hormones in RYGB-mediated effects have failed so far. For example, inhibition of a single gut hormone appears insufficient as the efficacy of RYGB is unaffected in GLP-1 receptor-knockout mice. ${ }^{41}$ Moreover, central blockade of GLP-1 receptors as well as blockade of PYY receptors also did not affect food intake in either sham-operated or RYGB-operated rats. ${ }^{41}$ Thus, there remains a certain level of uncertainty regarding the causal role of gut hormones for the observed changes in eating behavior after bariatric surgery, and it becomes evident that many different - partly unknown - factors may underlie the effects of RYGB surgery.

\section{Bile acids}

Levels of systemic bile acid concentrations are decreased in obese individuals. ${ }^{42}$ Bile acids act through various receptors, including the FXR and the TGR5, to influence nutrient metabolism and energy expenditure. RYGB normalizes postprandial plasma bile acid responses ${ }^{42}$ whereas systemic bile acid levels increase massively and may therefore be responsible for some RYGB-induced effects. ${ }^{8-10,43}$ Increased bile acids may also explain the increased secretion of GLP-1 and PYY after RYGB via TGR5 receptors located in the luminal membrane of L-cells. ${ }^{44}$ However, TGR5 stimulation would require a higher bile acid concentration in the intestinal lumen, which has not yet been shown. ${ }^{45} \mathrm{~A}$ causal contribution of bile acids to increased L-cell secretion after RYGB has also not yet been tested, and specific antagonists of TGR5 are currently not available. Experiments with TGR5 knockout mice undergoing RYGB are still awaited.

As bile acids increase energy expenditure in skeletal muscle and in brown adipose tissue, ${ }^{46}$ and because circulating bile acids are strongly correlated with postprandial energy expenditure in lean individuals, ${ }^{47}$ altered bile acid levels may contribute to changes in postprandial energy expenditure after RYGB.

In SG-operated mice, bile acid signaling via the FXR has been suggested to be a key determinant of body weight loss and glucose homeostasis. ${ }^{11}$ So far, similar studies have not yet been performed after RYGB.

\section{Gut microbiota}

Numerous studies in recent years have shown that metabolic processes mediated by the gut microbiome play an important role in whole-body metabolism in health and disease. ${ }^{12-14,48-50}$ The observation that fecal transfer of gut microbiota from obese donors can induce body weight gain in lean recipients has led to intensive research activities in recent years to investigate the role of the gut microbiome on the observed metabolic effects after bariatric surgery ${ }^{50}$ Changes in gut microbiota seem to directly contribute to reduced body weight and obesity after RYGB as transfer of gut microbiota from RYGB-treated mice to nonoperated, germ-free mice resulted in body weight loss and decreased fat mass in the recipient animals. ${ }^{13}$ In humans, variations of gut microbiota after RYGB are associated with changes in the expression of various genes in white adipose tissue, indicating a direct link 
between these two processes. ${ }^{21,51,52}$ Furthermore, postbariatric changes of the gut microbiome occur independently of body mass index (BMI) and result in altered levels of fecal and circulating metabolites compared with obese controls. ${ }^{14} \mathrm{By}$ colonizing germ-free mice with stools from the patients, the RYGB-altered microbiota promoted reduced fat deposition in recipient mice. ${ }^{14}$

An interaction between the gut microbiota and bile acid metabolism is probable as bile acids have known antibacterial effects. In addition, gut microbiota is known to be able to chemically modify endogenous bile acids to a number of different chemical species with different affinities at different bile acid receptors. ${ }^{53}$

\section{Energy expenditure}

Changes in energy expenditure after RYGB in humans are controversial. ${ }^{6,7,54,55}$ Thivel et $\mathrm{al}^{56}$ recently reviewed the available data on energy expenditure after bariatric surgery and concluded that the total energy expenditure in humans often decreases postoperatively due to the decrease in fat-free and fat mass, but that postprandial diet-induced thermogenesis is often increased. A few human studies suggest an increase in total energy expenditure after RYGB. ${ }^{6,7}$ Discrepancy in findings may be explained by the short duration of energy expenditure measurements and by the subsequent extrapolation of results to a 24-hour period; hence, true effects may have been missed. The necessary control groups were also not always included in the studies.

Compared to the human studies, data in rats and mice are more consistent, where RYGB seems to prevent or at least reduce the usual adaptive response (also known as "starvation response"), ie, body weight loss in RYGB rats is not associated with the same decrease in reduced energy expenditure that parallels weight loss by food restriction. ${ }^{3-5}$

RYGB and SG often produce similar changes in metabolism, ${ }^{57,58}$ but data indicate that changes in energy expenditure may not be an important contributor to body weight loss after SG. ${ }^{59,60}$ Furthermore, both clinical and animal studies have reported at least regain of body weight after $\mathrm{SG}$, which could be explained by differences in postoperative energy expenditure between RYGB and SG. ${ }^{60,61}$

The physiological mechanisms underlying altered energy expenditure after RYGB are only incompletely understood, although it seems evident that neither an increased spontaneous physical activity nor a general increase in body temperature due to postoperative inflammation plays a role. ${ }^{3}$ Instead, potential mechanisms include changes in gut hormone levels, ${ }^{3}$ altered brown adipose tissue activity, ${ }^{62}$ altered energy efficiency of skeletal muscle, or a higher energy requirement of hypertrophied small intestine. , $^{3,431,32,63}$

\section{Survey}

Surgical and nonsurgical members $(n=177)$ of the Swiss Society for the Study of Morbid Obesity and Metabolic Disorders representing 52 bariatric centers in Switzerland were formally invited by email to participate in the survey and to complete a nonvalidated, self-designed questionnaire. All responses that were received within 3 weeks after the initial contact were included in the analysis. In the questionnaire, participants were asked to indicate which of the following clinical conditions impacts their surgical treatment of choice to which degree $(0$ - no impact, 1 - minor impact, 3 - major impact):

1. Difficult to treat type 2 diabetes mellitus (T2DM), eg, high dosages of insulin or high HbA1c levels

2. $\mathrm{BMI}>50 \mathrm{~kg} / \mathrm{m}^{2}$

3. Concomitant hiatal herniation

4. Open abdominal surgery in patients' previous medical history

5. Increased anesthetic risk, ie, American Society of Anesthesiologists (ASA) $>$ III.

If the impact of these conditions was considered to be either minor or major, participants were further asked to indicate their preferred surgical technique in this situation (GB, SG, RYGB, or biliopancreatic diversion [BPD]). Responses favoring more than one operation were possible. The questionnaire was completed by 24 participants representing 24 different centers of bariatric surgery in Switzerland. The responses were obtained from $13.6 \%$ of Study of Morbid Obesity and Metabolic Disorders members and $46 \%$ of all Swiss bariatric centers.

About $79 \%$ of participants regarded the presence of severe T2DM as major and $21 \%$ as minor importance for their choice of surgical technique. Of these, the majority reported a preference for $\operatorname{RYGB}(n=20)$ over a BPD $(n=12)$ or SG $(n=7)$. None of the participants indicated GB as the operation of choice in this situation. A BMI $>50 \mathrm{~kg} / \mathrm{m}^{2}$ was considered to be of major importance by $66 \%$ of participants, whereas $33 \%$ regarded it as being of minor importance. In this situation, the majority of participants reported that they prefer an SG as their first option $(n=19)$ over an RYGB $(n=10)$ or a BPD ( $n=9)$. Again, none of the participants suggested GB.

In total, 33\% participants reported that the presence of a hiatal hernia has major impact on their choice of surgical technique, whereas $58 \%$ consider the presence of hiatal herniation as less important and $8 \%$ as not important at all 
for their decision. Of these, the majority of responders considered an RYGB as their preferred option $(n=18)$, whereas only five and three participants, respectively, consider an SG or BPD in this situation. None of the participants considered a GB for patients with hiatal herniation.

Previous open abdominal surgery was regarded to be of minor importance for decision-making by $63 \%$ of participants, whereas $33 \%$ attach no impact and $4 \%$ attach major impact to this clinical condition. However, the majority of responders preferred an $\mathrm{SG}(\mathrm{n}=16)$, whereas eight participants considered an RYGB and only one participant a BPD as potential options. In addition, two colleagues considered a GB as a potential option.

Finally, an increased anesthetic risk indicated by an ASA score $>$ III was given major importance by $42 \%$ and minor importance by $46 \%$ of the participants. Interestingly, $13 \%$ of the participants consider anesthetic risk as not important at all. In patients with increased anesthetic risk (ASA > III), most participants chose $\mathrm{SG}(\mathrm{n}=16)$, whereas fewer participants considered an RYGB ( $n=8)$, a GB $(n=2)$, or a BPD operation $(n=1)$ as the preferred option.

\section{Current evidence to support results of the survey Type 2 diabetes mellitus}

Bariatric surgery has been shown to induce and maintain normoglycemia in obese patients suffering from T2DM more effectively than any present medical therapy alone for 5 years. ${ }^{64-67}$ The results obtained from our survey suggest that bariatric surgeons consider severe T2DM as an important factor when it comes to the choice of bariatric procedure. However, the question of whether one single bariatric procedure is superior to all other procedures in patients with T2DM is challenging as many factors need to be considered.

The best evidence for T2DM remission is available for RYGB and SG. In the study of Schauer et al, ${ }^{66,67}$ both bariatric surgeries improved glycemic control; however, the number of patients with normal $\mathrm{HbAlc}$ without antidiabetic medication was significantly higher 3 years after RYGB than after SG (28 vs $16, P>0.01) .{ }^{66} \mathrm{RYGB}$ was also more effective than $\mathrm{SG}$ in terms of $\mathrm{HbA} 1 \mathrm{c}$ reduction and partial remission of T2DM. ${ }^{68}$ Other randomized controlled trials showed glycemic control to a similar extent for both surgical procedures. ${ }^{57,69-73}$

Jimenez et $\mathrm{al}^{74}$ performed continuous glucose monitoring after ingestion of a standardized liquid mixed meal. They observed an earlier and higher peak of serum glucose levels in RYGB patients. Moreover, RYGB patients spent more time in a hypoglycemic state than patients after SG. ${ }^{74}$ Both high glucose peaks as well as the fast changes from hyper- to hypoglycemic state are considered undesirable, as such an abnormal postprandial glucose profile may be associated with higher rates of relapse of diabetes over time. However, this has not been shown so far. In contrast, recent data suggest that relapse of diabetes might be higher after SG than after RYGB. ${ }^{66}$

Interestingly, $50 \%$ of all bariatric surgeons in our survey considered BPD in case of severe metabolic disorder. However, BPD is only performed by a few surgeons due to an increased risk for surgical complications and long-term side effects such as diarrhea or micronutrient deficiencies. ${ }^{75}$ Although the study of Mingrone et al ${ }^{65}$ was primarily designed to compare medical with surgical treatment, it revealed that the remission rate of T2DM was higher and that relapse of hyperglycemia was lower 5 years after BPD than after RYGB. ${ }^{65}$

In contrast to RYGB and $\mathrm{SG}, \mathrm{GB}$ has lost much of its initial attraction, although a randomized controlled trial by Dixon et $\mathrm{al}^{76}$ showed that $73 \%$ of recently diagnosed patients with T2DM achieve diabetic remission 2 years after their GB operation.

In summary, the evidence that bariatric surgery alone or in combination with best medical care is superior for the treatment of T2DM when compared to best medical care alone is undisputed. ${ }^{77}$ RYGB and SG seem to offer the best risk-benefit ratio, as other procedures such as BPD and GB are characterized in some setting by high complication rates and/or high numbers of reoperations. ${ }^{30}$

\section{Severe obesity}

Morbidly obese patients loose more weight after RYGB and SG operations than after laparoscopic adjustable GB, irrespective of their initial BMI. ${ }^{78-81}$ A multivariate regression analysis of the Bariatric Outcomes Longitudinal Database including 31443 laparoscopic adjustable GB, 40352 RYGB, and 2194 SG patients demonstrated that the type of bariatric surgery is the most important predictor of postoperative weight loss. Weight loss was highest after RYGB across all levels of body weight and significantly lower after GB. SG was underrepresented in this study, and thus comparison with RYGB was not possible. ${ }^{78}$ BPD was also not included in this analysis.

A systematic review including studies with $>100$ patients published before 2005 revealed that banded RYGB, a modification of RYGB with placement of a nonadjustable or adjustable band around the gastric pouch, and BPD showed the best results in terms of weight loss 3 years after surgery. The lack 
of long-term follow-up data and data of SG are important limitations of this study. ${ }^{82}$

SG, RYGB, and BPD are more effective in inducing and maintaining weight loss in patients with BMI $>50 \mathrm{~kg} / \mathrm{m}^{2}$, which is consistent with the results of our survey. Despite the fact that the existing evidence suggests a greater body weight loss after RYGB than after SG, the majority of bariatric surgeons in our survey favored SG for superobese patients, possibly because of technical considerations. The creation of gastrojejunostomy, which has to be performed for RYGB, can be challenging in this subgroup due to a large left liver lobe ${ }^{83,84}$ or accentuated visceral fat. ${ }^{85}$ Moreover, an SG can still be converted into an RYGB, if primary weight loss is insufficient or weight regain occurs. ${ }^{83}$ However, surgeons seem to place more importance on perceived safety and the avoidance of possible postsurgical side effects as one important guiding factor for the choice of the procedures.

\section{Concomitant hiatal hernia}

The prevalence of gastroesophageal reflux disease (GERD) in patients with morbid obesity is as high as $45 \% .{ }^{86}$ GERD in morbidly obese patients is often associated or explained by the presence of a hiatal hernia. ${ }^{87}$ Hiatal hernias can be expected in up to $38.5 \%$ of patients undergoing bariatric surgery. ${ }^{88}$ The effect of different bariatric procedures on the resolution of GERD was investigated by Pallati et al, ${ }^{89}$ who found that the Savary-Miller GERD score improved after all procedures, with the best results being obtained after RYGB (56\% of patients) when compared to GB (46\%) and SG (41\%). GERD symptoms in some SG patients deteriorated, whereas RYGB and Nissen fundoplication were found to be equally effective for the treatment of GERD in obese patients with hiatal hernia. ${ }^{90}$ Nearly all the participants of our survey considered hiatal hernia before deciding on the surgical technique.

\section{Previous laparotomy}

As every previous laparotomy increases the risk and extent of intra-abdominal adhesions, ${ }^{91}$ the technical difficulty and subsequent risk for complications of a laparoscopic approach may increase, too. However, the way this influences the surgeons' choice has never been formally investigated in the context of bariatric surgery. A retrospective study of 139 patients who underwent laparoscopy-assisted gastrectomy for early gastric cancer demonstrated that history of laparotomy was not associated with increased postoperative complications. ${ }^{92}$ However, $80 \%$ of these previous laparotomies were due to appendectomies and gynecological operations. Moreover, operations were performed in a lean population; thus, the results may not be representative for a bariatric population where surgery is mainly limited to the upper gastrointestinal tract.

Our survey showed that a history of previous laparotomies impacts on the choice of bariatric procedure, although it was regarded only as a minor factor. The majority of participating surgeons favored SG, when faced with (several) previous laparotomies, probably intending to avoid complex adhesiolysis of the lower abdomen, which might be necessary for the lower anastomosis in case of RYGB or BPD.

\section{Increased anesthesiological risk (ASA > III)}

ASA class $\geq \mathrm{III}$ is an independent predictor of postoperative complications after RYGB. ${ }^{93,94}$ Interestingly, postoperative pulmonary complications differ significantly between RYGB $(1.3 \%)$, SG $(0.84 \%)$, and GB $(0.3 \%)$, which may reflect differences in the duration of surgery. ${ }^{94}$

The majority of participants of our survey consider a high anesthetic risk when they decide on the type of bariatric surgery. The majority of surgeons tend to prefer SG when the ASA score is >III whereas a small group of surgeons opted for GB in this situation. Differences may be explained by the intention to reduce operation time, which may be shorter for SG than RYGB, ${ }^{94}$ and also to reduce the risk for postoperative anastomotic complications. Of course, operation time for $\mathrm{GB}$ is the shortest. ${ }^{94}$

\section{Conclusion}

Metabolic surgery is currently the most effective treatment for morbid obesity and its concomitant diseases. The armory should include RYGB, SG, BPD, and GB. Traditionally, the effects of bariatric surgery were explained by caloric malabsorption and mechanical restriction. However, animal and human studies challenged these mechanical explanations. Instead, other physiological mechanisms seem to be at play, such as alterations in gut hormone levels, changes in bile acid concentration, an altered composition of gut microbiota, as well as changes in energy expenditure. All these seem to contribute to the beneficial effects of bariatric surgery. The different effects of surgical procedures on body weight and comorbidities such as T2DM may be explained by the specific mechanisms of these operations, but more work is required to fully understand each contribution.

A survey among Swiss surgeons and clinical practitioners revealed that T2DM and BMI are major criteria considered during the choice of bariatric surgeries. In case of T2DM, most of the participants prefer RYGB over BPD as it has fewer 
side effects, such as hypoproteinemia and diarrhea, although offering preferable improvements in terms of glycemic control. While T2DM remission rate seems slightly higher after RYGB, the smaller glucose excursions after food intake after SG may have benefits. Similarly, in case of a BMI $>50$ $\mathrm{kg} / \mathrm{m}^{2}$, the risk-benefit ratio seems best for SG and RYGB. Technical considerations like a large left liver lobe and the option of a later conversion to RYGB may be considered as reasons to rather perform a SG. Surgeons seem to prioritize perceived safety and avoidance of postsurgical side effects before selecting the procedure.

The presence of GERD should encourage surgeons to perform RYGB because of its beneficial and weightindependent effects on GERD. Most participants of the survey prefer SG in cases of high anesthetic risk (ASA > III) and previous laparotomy in the patients' history. In summary, choice of surgical procedure can be challenging as several competing factor requires consideration. Although consensus is emerging, no clear decision tree has been established as the underlying evidence is still lacking.

\section{Disclosure}

The authors report no conflicts of interests in this work.

\section{References}

1. le Roux CW, Aylwin SJ, Batterham RL, et al. Gut hormone profiles following bariatric surgery favor an anorectic state, facilitate weight loss, and improve metabolic parameters. Ann Surg. 2006;243(1):108-114.

2. le Roux CW, Welbourn R, Werling M, et al. Gut hormones as mediators of appetite and weight loss after Roux-en-Y gastric bypass. Ann Surg. 2007;246(5):780-785.

3. Bueter M, Lowenstein C, Olbers T, et al. Gastric bypass increases energy expenditure in rats. Gastroenterology. 2010;138(5):1845-1853.

4. Saeidi N, Meoli L, Nestoridi E, et al. Reprogramming of intestinal glucose metabolism and glycemic control in rats after gastric bypass. Science. 2013;341(6144):406-410.

5. Stylopoulos N, Hoppin AG, Kaplan LM. Roux-en-Y gastric bypass enhances energy expenditure and extends lifespan in diet-induced obese rats. Obesity (Silver Spring). 2009;17(10):1839-1847.

6. Werling M, Fandriks L, Olbers T, et al. Roux-en-Y gastric bypass surgery increases respiratory quotient and energy expenditure during food intake. PLoS One. 2015;10(6):e0129784.

7. Werling M, Olbers T, Fandriks L, et al. Increased postprandial energy expenditure may explain superior long term weight loss after Roux-enY gastric bypass compared to vertical banded gastroplasty. PLoS One. 2013;8(4):e60280.

8. Glicksman C, Pournaras DJ, Wright M, et al. Postprandial plasma bile acid responses in normal weight and obese subjects. Ann Clin Biochem. 2010;47(Pt 5):482-484.

9. Pournaras DJ, Glicksman C, Vincent RP, et al. The role of bile after Roux-en-Y gastric bypass in promoting weight loss and improving glycaemic control. Endocrinology. 2012;153(8):3613-3619.

10. Pournaras DJ, le Roux CW. Are bile acids the new gut hormones? Lessons from weight loss surgery models. Endocrinology. 2013;154(7): 2255-2256.

11. Ryan KK, Tremaroli V, Clemmensen C, et al. FXR is a molecular target for the effects of vertical sleeve gastrectomy. Nature. 2014;509(7499): $183-188$.
12. Li JV, Ashrafian H, Bueter M, et al. Metabolic surgery profoundly influences gut microbial-host metabolic cross-talk. Gut. 2011;60(9): 1214-1223.

13. Liou AP, Paziuk M, Luevano JM Jr, Machineni S, Turnbaugh PJ, Kaplan LM. Conserved shifts in the gut microbiota due to gastric bypass reduce host weight and adiposity. Sci Transl Med. 2013;5(178):178ra141.

14. Tremaroli V, Karlsson F, Werling M, et al. Roux-en-Y gastric bypass and vertical banded gastroplasty induce long-term changes on the human gut microbiome contributing to fat mass regulation. Cell Metab. 2015;22(2):228-238.

15. Angrisani L, Santonicola A, Iovino P, Formisano G, Buchwald H, Scopinaro N. Bariatric surgery worldwide 2013. Obes Surg. 2015;25(10): $1822-1832$.

16. Weber M, Muller MK, Bucher T, et al. Laparoscopic gastric bypass is superior to laparoscopic gastric banding for treatment of morbid obesity. Ann Surg. 2004;240(6):975-982; discussion 982-973.

17. Gumbs AA, Gagner M, Dakin G, Pomp A. Sleeve gastrectomy for morbid obesity. Obes Surg. 2007;17(7):962-969.

18. Bueter M, le Roux CW. Gastrointestinal hormones, energy balance and bariatric surgery. Int J Obes (Lond). 2011;35(Suppl 3):S35-S39.

19. Korner J, Bessler M, Cirilo LJ, et al. Effects of Roux-en-Y gastric bypass surgery on fasting and postprandial concentrations of plasma ghrelin, peptide YY, and insulin. J Clin Endocrinol Metab. 2005;90(1): 359-365.

20. Li F, Jiang C, Krausz KW, et al. Microbiome remodelling leads to inhibition of intestinal farnesoid $\mathrm{X}$ receptor signalling and decreased obesity. Nat Commun. 2013;4:2384.

21. Osto M, Abegg K, Bueter M, le Roux CW, Cani PD, Lutz TA. Rouxen-Y gastric bypass surgery in rats alters gut microbiota profile along the intestine. Physiol Behav. 2013;119:92-96.

22. Laferrere B, Heshka $S$, Wang $K$, et al. Incretin levels and effect are markedly enhanced 1 month after Roux-en-Y gastric bypass surgery in obese patients with type 2 diabetes. Diabetes Care. 2007;30(7):1709-1716.

23. Lutz TA, Bueter M. The physiology underlying Roux-en-Y gastric bypass: a status report. Am J Physiol Regul Integr Comp Physiol. 2014; 307(11):R1275-R1291.

24. Asarian L, Bachler T. Neuroendocrine control of satiation. Horm Mol Biol Clin Investig. 2014;19(3):163-192.

25. Atkinson RL, Brent EL. Appetite suppressant activity in plasma of rats after intestinal bypass surgery. Am J Physiol. 1982;243(1): R60-R64.

26. Pournaras DJ, Osborne A, Hawkins SC, et al. The gut hormone response following Roux-en-Y gastric bypass: cross-sectional and prospective study. Obes Surg. 2010;20(1):56-60.

27. Behary P, Cegla J, Tan TM, Bloom SR. Obesity: lifestyle management, bariatric surgery, drugs, and the therapeutic exploitation of gut hormones. Postgrad Med. 2015;127(5):494-502.

28. le Roux CW, Batterham RL, Aylwin SJ, et al. Attenuated peptide YY release in obese subjects is associated with reduced satiety. Endocrinology. 2006;147(1):3-8.

29. Shin AC, Zheng H, Townsend RL, Sigalet DL, Berthoud HR. Mealinduced hormone responses in a rat model of Roux-en-Y gastric bypass surgery. Endocrinology. 2010;151(4):1588-1597.

30. Dimitriadis E, Daskalakis M, Kampa M, Peppe A, Papadakis JA, Melissas J. Alterations in gut hormones after laparoscopic sleeve gastrectomy: a prospective clinical and laboratory investigational study. Ann Surg. 2013;257(4):647-654.

31. Hansen CF, Bueter M, Theis N, et al. Hypertrophy dependent doubling of L-cells in Roux-en-Y gastric bypass operated rats. PLoS One. 2013;8(6):e65696

32. Mumphrey MB, Patterson LM, Zheng H, Berthoud HR. Roux-en-Y gastric bypass surgery increases number but not density of CCK-, GLP-1-, 5-HT-, and neurotensin-expressing enteroendocrine cells in rats. Neurogastroenterol Motil. 2013;25(1):e70-e79.

33. Dirksen C, Jorgensen NB, Bojsen-Moller KN, et al. Gut hormones, early dumping and resting energy expenditure in patients with good and poor weight loss response after Roux-en-Y gastric bypass. Int $J$ Obes (Lond). 2013;37(11):1452-1459. 
34. Fenske WK, Bueter M, Miras AD, Ghatei MA, Bloom SR, le Roux CW. Exogenous peptide YY3-36 and Exendin-4 further decrease food intake, whereas octreotide increases food intake in rats after Roux-en-Y gastric bypass. Int J Obes (Lond). 2011.

35. Elliott JA, Jackson S, King S, et al. Gut hormone suppression increases food intake after esophagectomy with gastric conduit reconstruction. Ann Surg. 2015;262(5):824-830.

36. Laurenius A, Larsson I, Melanson KJ, et al. Decreased energy density and changes in food selection following Roux-en-Y gastric bypass. Eur J Clin Nutr. 2013;67(2):168-173.

37. Adrian TE, Gariballa S, Parekh KA, et al. Rectal taurocholate increases $\mathrm{L}$ cell and insulin secretion, and decreases blood glucose and food intake in obese type 2 diabetic volunteers. Diabetologia. 2012;55(9): 2343-2347.

38. Hirasawa A, Tsumaya K, Awaji T, et al. Free fatty acids regulate gut incretin glucagon-like peptide-1 secretion through GPR120. Nat Med. 2005;11(1):90-94.

39. Thomas C, Gioiello A, Noriega L, et al. TGR5-mediated bile acid sensing controls glucose homeostasis. Cell Metab. 2009;10(3):167-177.

40. Tadross JA, le Roux CW. The mechanisms of weight loss after bariatric surgery. Int J Obes. 2009;33(Suppl 1):S28-S32.

41. Ye J, Hao Z, Mumphrey MB, et al. GLP-1 receptor signaling is not required for reduced body weight after RYGB in rodents. Am J Physiol Regul Integr Comp Physiol. 2014;306(5):R352-R362.

42. Ahmad NN, Pfalzer A, Kaplan LM. Roux-en-Y gastric bypass normalizes the blunted postprandial bile acid excursion associated with obesity. Int J Obes. 2013;37(12):1553-1559.

43. Kohli R, Myronovych A, Tan BK, et al. Bile acid signaling: mechanism for bariatric surgery, cure for NASH? Dig Dis. 2015;33(3):440-446.

44. Duboc H, Tache Y, Hofmann AF. The bile acid TGR5 membrane receptor: from basic research to clinical application. Dig Liver Dis. 2014;46(4):302-312.

45. Parker HE, Wallis K, le Roux CW, Wong KY, Reimann F, Gribble FM. Molecular mechanisms underlying bile acid-stimulated glucagon-like peptide-1 secretion. Br J Pharmacol. 2012;165(2):414- 423.

46. Watanabe M, Houten SM, Mataki C, et al. Bile acids induce energy expenditure by promoting intracellular thyroid hormone activation. Nature. 2006;439(7075):484-489.

47. Ockenga J, Valentini L, Schuetz T, et al. Plasma bile acids are associated with energy expenditure and thyroid function in humans. $J$ Clin Endocrinol Metab. 2012;97(2):535-542.

48. Backhed F, Ding H, Wang T, et al. The gut microbiota as an environmental factor that regulates fat storage. Proc Natl Acad Sci USA. 2004;101(44): $15718-15723$

49. Li JV, Reshat R, Wu Q, et al. Experimental bariatric surgery in rats generates a cytotoxic chemical environment in the gut contents. Front Microbiol. 2011;2:183.

50. Turnbaugh PJ, Ley RE, Mahowald MA, Magrini V, Mardis ER, Gordon JI. An obesity-associated gut microbiome with increased capacity for energy harvest. Nature. 2006;444(7122):1027-1031.

51. Furet JP, Kong LC, Tap J, et al. Differential adaptation of human gut microbiota to bariatric surgery-induced weight loss: links with metabolic and low-grade inflammation markers. Diabetes. 2010;59(12): 3049-3057.

52. Kong LC, Tap J, Aron-Wisnewsky J, et al. Gut microbiota after gastric bypass in human obesity: increased richness and associations of bacterial genera with adipose tissue genes. Am J Clin Nutr. 2013;98(1):16-24.

53. Camilleri M, Gores GJ. Therapeutic targeting of bile acids. Am J Physiol Gastrointest Liver Physiol. 2015;309(4):G209-215.

54. Carrasco F, Papapietro K, Csendes A, et al. Changes in resting energy expenditure and body composition after weight loss following Rouxen-Y gastric bypass. Obes Surg. 2007;17(5):608-616.

55. Das SK, Roberts SB, McCrory MA, et al. Long-term changes in energy expenditure and body composition after massive weight loss induced by gastric bypass surgery. Am J Clin Nutr. 2003;78(1):22-30.

56. Thivel D, Brakonieki K, Duche P, Morio B, Boirie Y, Laferrere B. Surgical weight loss: impact on energy expenditure. Obes Surg. 2013;23(2):255-266.
57. Peterli R, Borbely Y, Kern B, et al. Early results of the Swiss Multicentre Bypass or Sleeve Study (SM-BOSS): a prospective randomized trial comparing laparoscopic sleeve gastrectomy and Roux-en-Y gastric bypass. Ann Surg. 2013;258(5):690-694; discussion 695.

58. Peterli R, Steinert RE, Woelnerhanssen B, et al. Metabolic and hormonal changes after laparoscopic Roux-en-Y gastric bypass and sleeve gastrectomy: a randomized, prospective trial. Obes Surg. 2012;22(5):740-748.

59. Saeidi N, Nestoridi E, Kucharczyk J, Uygun MK, Yarmush ML, Stylopoulos N. Sleeve gastrectomy and Roux-en-Y gastric bypass exhibit differential effects on food preferences, nutrient absorption and energy expenditure in obese rats. Int J Obes (Lond). 2012;36(11):1396-1402.

60. Stefater MA, Perez-Tilve D, Chambers AP, et al. Sleeve gastrectomy induces loss of weight and fat mass in obese rats, but does not affect leptin sensitivity. Gastroenterology. 2010;138(7):2426-2436, 2436 e2421-2423.

61. Alvarez V, Carrasco F, Cuevas A, et al. Mechanisms of long-term weight regain in patients undergoing sleeve gastrectomy. Nutrition. 2016;32(3):303-308.

62. Hankir M, Bueter M, Gsell W, et al. Increased energy expenditure in gastric bypass rats is not caused by activated brown adipose tissue. Obes Facts. 2012;5(3):349-358.

63. le Roux CW, Borg CM, Wallis K, et al. Gut hypertrophy after gastric bypass is associated with increased glucagon-like peptide 2 and intestinal crypt cell proliferation. Ann Surg. 2010;252(1):50-56.

64. Mingrone G, Panunzi S, De Gaetano A, et al. Bariatric surgery versus conventional medical therapy for type 2 diabetes. $N$ Engl $J$ Med. 2012;366(17):1577-1585

65. Mingrone G, Panunzi S, De Gaetano A, et al. Bariatric-metabolic surgery versus conventional medical treatment in obese patients with type 2 diabetes: 5 year follow-up of an open-label, single-centre, randomised controlled trial. Lancet. 2015;386(9997):964-973.

66. Schauer PR, Bhatt DL, Kirwan JP, et al. Bariatric surgery versus intensive medical therapy for diabetes -3 -year outcomes. $N$ Engl J Med. 2014;370:2002-2013.

67. Schauer PR, Kashyap SR, Wolski K, et al. Bariatric surgery versus intensive medical therapy in obese patients with diabetes. $N$ Engl $J$ Med. 2012;366(17):1567-1576.

68. Chang SH, Stoll CR, Song J, Varela JE, Eagon CJ, Colditz GA. The effectiveness and risks of bariatric surgery: an updated systematic review and meta-analysis, 2003-2012. JAMA Surg. 2014;149(3):275-287.

69. Helmio M, Victorzon M, Ovaska J, et al. Comparison of short-term outcome of laparoscopic sleeve gastrectomy and gastric bypass in the treatment of morbid obesity: A prospective randomized controlled multicenter SLEEVEPASS study with 6-month follow-up. Scand $J$ Surg. 2014;103(3):175-181.

70. Karamanakos SN, Vagenas K, Kalfarentzos F, Alexandrides TK. Weight loss, appetite suppression, and changes in fasting and postprandial ghrelin and peptide-YY levels after Roux-en-Y gastric bypass and sleeve gastrectomy: a prospective, double blind study. Ann Surg. 2008;247(3):401-407.

71. Kehagias I, Karamanakos SN, Argentou M, Kalfarentzos F. Randomized clinical trial of laparoscopic Roux-en-Y gastric bypass versus laparoscopic sleeve gastrectomy for the management of patients with BMI $<50 \mathrm{~kg} / \mathrm{m}^{2}$. Obes Surg. 2011;21(11):1650-1656.

72. Keidar A, Hershkop KJ, Marko L, et al. Roux-en-Y gastric bypass vs sleeve gastrectomy for obese patients with type 2 diabetes: a randomised trial. Diabetologia. 2013;56(9):1914-1918.

73. Paluszkiewicz R, Kalinowski P, Wroblewski T, et al. Prospective randomized clinical trial of laparoscopic sleeve gastrectomy versus open Roux-en-Y gastric bypass for the management of patients with morbid obesity. Wideochir Inne Tech Maloinwazyjne. 2012;7(4):225-232.

74. Jimenez A, Ceriello A, Casamitjana R, Flores L, Viaplana-Masclans J, Vidal J. Remission of type 2 diabetes after Roux-en-Y gastric bypass or sleeve gastrectomy is associated with a distinct glycemic profile. Ann Surg. 2015;261(2):316-322.

75. Sovik TT, Taha O, Aasheim ET, et al. Randomized clinical trial of laparoscopic gastric bypass versus laparoscopic duodenal switch for superobesity. Br J Surg. 2010;97(2):160-166. 
76. Dixon JB, O'Brien PE, Playfair J, et al. Adjustable gastric banding and conventional therapy for type 2 diabetes: a randomized controlled trial. JAMA. 2008;299(3):316-323.

77. Fischer L, Wekerle AL, Bruckner T, et al. BariSurg trial: Sleeve gastrectomy versus Roux-en-Y gastric bypass in obese patients with BMI $35-60 \mathrm{~kg} / \mathrm{m}(2)$ - a multi-centre randomized patient and observer blind non-inferiority trial. BMC Surg. 2015;15:87.

78. Benoit SC, Hunter TD, Francis DM, De La Cruz-Munoz N. Use of bariatric outcomes longitudinal database (BOLD) to study variability in patient success after bariatric surgery. Obes Surg. 2014;24(6):936-943.

79. Davies SW, Efird JT, Guidry CA, et al. Twenty-first century weight loss: banding versus bypass. Surg Endosc. 2015;29(4):947-954.

80. Giordano S, Tolonen P, Victorzon M. Laparoscopic Roux-en-Y gastric bypass versus laparoscopic adjustable gastric banding in the super-obese: peri-operative and early outcomes. Scand J Surg. 2015;104(1):5-9.

81. Franco JV, Ruiz PA, Palermo M, Gagner M. A review of studies comparing three laparoscopic procedures in bariatric surgery: sleeve gastrectomy, Roux-en-Y gastric bypass and adjustable gastric banding. Obes Surg. 2011;21(9):1458-1468.

82. O'Brien PE, McPhail T, Chaston TB, Dixon JB. Systematic review of medium-term weight loss after bariatric operations. Obes Surg. 2006;16(8):1032-1040.

83. Nguyen NT, Longoria M, Gelfand DV, Sabio A, Wilson SE. Staged laparoscopic Roux-en-Y: a novel two-stage bariatric operation as an alternative in the super-obese with massively enlarged liver. Obes Surg. 2005;15(7):1077-1081.

84. Schwartz ML, Drew RL, Chazin-Caldie M. Factors determining conversion from laparoscopic to open Roux-en-Y gastric bypass. Obes Surg 2004;14(9):1193-1197.

85. Nguyen NT, Rivers R, Wolfe BM. Factors associated with operative outcomes in laparoscopic gastric bypass. J Am Coll Surg. 2003;197(4): 548-555; discussion 555-547.
86. Ogden CL, Yanovski SZ, Carroll MD, Flegal KM. The epidemiology of obesity. Gastroenterology. 2007;132(6):2087-2102.

87. Che F, Nguyen B, Cohen A, Nguyen NT. Prevalence of hiatal hernia in the morbidly obese. Surg Obes Relat Dis. 2013;9(6):920-924.

88. Heacock L, Parikh M, Jain R, Balthazar E, Hindman N. Improving the diagnostic accuracy of hiatal hernia in patients undergoing bariatric surgery. Obes Surg. 2012;22(11):1730-1733.

89. Pallati PK, Shaligram A, Shostrom VK, Oleynikov D, McBride CL, Goede MR. Improvement in gastroesophageal reflux disease symptoms after various bariatric procedures: review of the Bariatric Outcomes Longitudinal Database. Surg Obes Relat Dis. 2014;10(3):502-507.

90. Patterson EJ, Davis DG, Khajanchee Y, Swanstrom LL. Comparison of objective outcomes following laparoscopic Nissen fundoplication versus laparoscopic gastric bypass in the morbidly obese with heartburn. Surg Endosc. 2003;17(10):1561-1565.

91. Strik C, Stommel MW, Ten Broek RP, van Goor H. Adhesiolysis in patients undergoing a repeat median laparotomy. Dis Colon Rectum. 2015;58(8):792-798.

92. Nunobe S, Hiki N, Fukunaga T, et al. Previous laparotomy is not a contraindication to laparoscopy-assisted gastrectomy for early gastric cancer. World J Surg. 2008;32(7):1466-1472.

93. Hutter MM, Randall S, Khuri SF, Henderson WG, Abbott WM, Warshaw AL. Laparoscopic versus open gastric bypass for morbid obesity: a multicenter, prospective, risk-adjusted analysis from the National Surgical Quality Improvement Program. Ann Surg. 2006;243(5):657-662; discussion 662-656.

94. Schumann R, Shikora SA, Sigl JC, Kelley SD. Association of metabolic syndrome and surgical factors with pulmonary adverse events, and longitudinal mortality in bariatric surgery. Br JAnaesth. 2015;114(1): $83-90$.

95. Lutz T, Bueter M. Wohin geht die Anti-Obesitas Therapie? Prakt Tierarzt. 2012;93(12):1087-1095.
Clinical and Experimental Gastroenterology

\section{Publish your work in this journal}

Clinical and Experimental Gastroenterology is an international, peerreviewed, open access, online journal publishing original research, reports, editorials, reviews and commentaries on all aspects of gastroenterology in the clinic and laboratory. This journal is included on PubMed. The manuscript management system is completely online

\section{Dovepress}

and includes a very quick and fair peer-review system, which is all easy to use. Visit http://www.dovepress.com/testimonials.php to read real quotes from published authors. 